\title{
An Evaluation of Educational Development in Sistan and Baluchestan Province
}

\author{
Ali Reza Mir, Mahmoud Reza Anvari*, Gholam Reza Miri \\ Department of Geography and Urban Planning, Faculty of Humanities, Islamic Azad University, \\ Zahedan Branch, Zahedan, Iran \\ Email: *rezaanvari2000@yahoo.co.in
}

Received 10 February 2016; accepted 26 March 2016; published 29 March 2016

Copyright (C) 2016 by authors and Scientific Research Publishing Inc.

This work is licensed under the Creative Commons Attribution International License (CC BY). http://creativecommons.org/licenses/by/4.0/

(c) (i) Open Access

\begin{abstract}
Every country tries for development because it is considered necessary and essential by most people. Economic development is only one type, meaning that development is not only an economic phenomenon. In order to strengthen development foundations, most countries need to pay attention to other aspects of development including the level of education. This article aims to measure and rank relative level of educational development in Sistan and Baluchistan (S \& B) Province, Iran using 18 educational indicators. An applied, descriptive, documentary, and analytical study was performed. Documentary method and S\&B education statistics were utilized to collect the data. We also used Morris model to analyze data and determine the level of development, educational ranks, and the relationship between variables. Then, we rated educational development in seven mentioned cities in $\mathbf{S} \&$ B by creating values in ArcGIS. Concerning educational development, findings indicated that Zahedan scored the top, while Nikshahr ranked the last. As a result, an inequality is found among these cities and planning is felt ever than before to reduce such inequality.
\end{abstract}

\section{Keywords}

Final Educational, Rank, Development, Sistan and Baluchistan Province, Morris

\section{Introduction}

The achievement of national development depends on the exposure and synchronized movement and development gap reduction of all regions and cities in development process. Education is also traditionally known as one of the main pillars and determinants of economic and social development. In addition, technological ad-

\footnotetext{
Corresponding author.
} 
vances and new methods of production in recent years which have changed the world's economic systems and their relationship caused the central role of education more important in development. In fact, innovation and application of new technologies and methods of production depend on well-trained and intellectually flexible labor force. This shows the need for more investment in education (Ismaili, 1998: 2). In Iran's educational system, almost one million and 130 thousands principals, deputy, consultant, trainers, teachers, and other employees are in charge of more than 114 thousand students with total budget of more than 140 thousand billion Rials $^{1}$. In the last few decades, multiple economic, social, political, and cultural studies have been conducted for educational development and its dimensions. It is also considered a separator factor in countries (Tavakoli et al., 2012: p. 488).

The study of economic, social, cultural, and educational inequalities among groups, classes, geographical regions, or political divisions is one of essential tasks to plan and reform in order to reach economic growth and social justice. In this regard, planners are required to take balanced distribution of facilities into account as the basis of planning (Saraki, 1996: p. 53).

Examining variables, facilities, and capabilities in different areas, we are able to determine the level of utilization concerning educational facilities, resources, and opportunities. Identifying failures and shortcomings would help clarify investment priorities in order to achieve social justice development. It is obvious that extending and expanding education in poor areas lacking facilities will lead to cultural movement, leaving positive effects to promote the level of culture, provided that the education authorities will make rational decision and planning in order to eliminate or reduce educational inequalities. To this end, it is necessary to rank educational regions concerning educational development to clarify and determine regions which need higher level of attention by appropriate planning and strategies. According to above mentioned issues, this article aims to rank cities in S\&B concerning educational development, compare the cities in terms of educational development, and prioritize planning for the mentioned cities. Evaluation is one of accepted tools for convenience planning for planners, principals, and decision-makers in order to identify potential effects of education in sustainable development and select the best and logical choice for educational development. To this end, this article aims to evaluate educational development in five cities in Sistan and Baluchistan Province including Iranshahr, Chabahar, Khash, Zabol, Zahedan, Saravan, and Nikshahr.

\section{Methodology}

Sistan and Baluchistan province is located in south east part of Iran (Figure 1 \& Figure 2). The latitude varies from $25^{\circ} 3^{\prime}$ to $31^{\circ} 2^{\prime} \mathrm{N}$ and the longitude varies from $58^{\circ} 49^{\prime}$ to $63^{\circ} 20^{\prime} \mathrm{E}$. Sistan and Baluchistan borders South

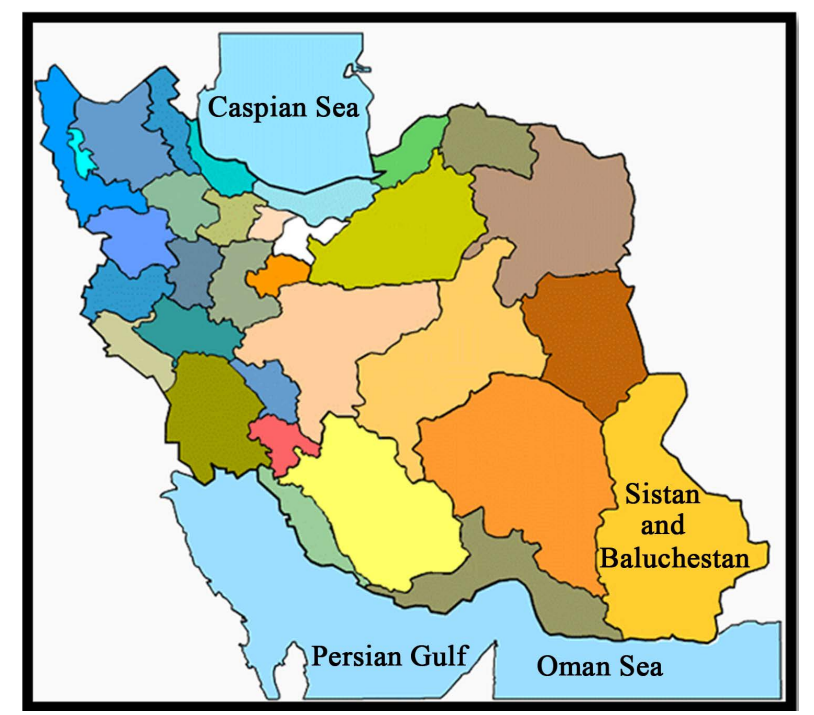

Figure 1. The geographical location of Sistan and Baluchistan province in Iran. Source 1: Book of Sistan and Baluchestan Province.

${ }^{1}$ Iranian Currency. 


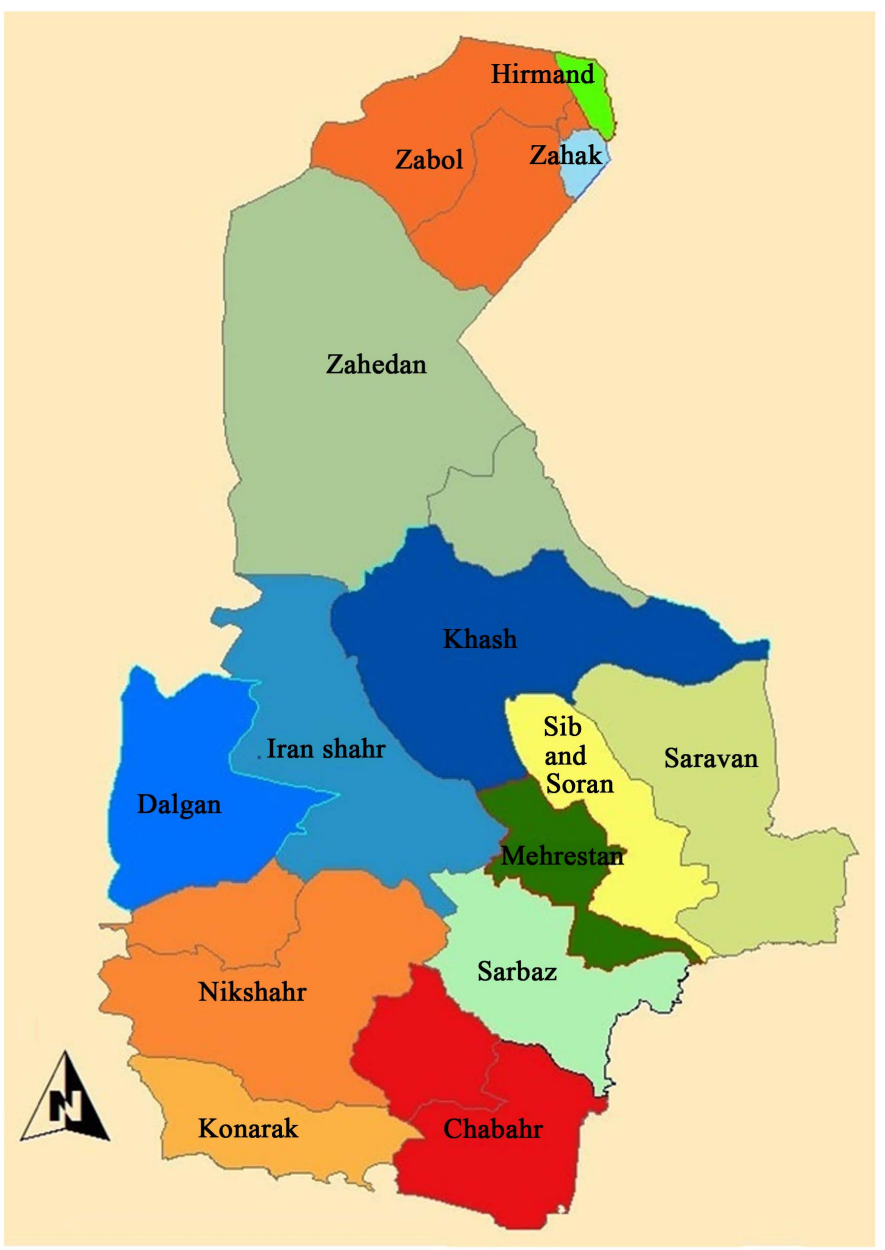

Figure 2. The geographical location of the Cities of Sistan and Baluchestan Province. Source 2: Book of Sistan and Baluchestan Province.

Khorasan and Afghanistan to north, $1200 \mathrm{~km}$ land and sea with Pakistan and Afghanistan to east, 300-km sea border with the Gulf of Oman, and Kerman and Hormozgan provinces to west. This largest province covers $181,785 \mathrm{~km}^{2}$ which is $11.3 \%$ of total area of Iran. The northern part of the province in influenced the Quaternary period, while the central part is mountainous. The southern part is influenced by Tertiary period. The average annual precipitation is almost $110 \mathrm{~mm}$. Therefore, it is considered dry and semi-dry region. The land experiences lack of water due to low precipitation level. The weather is generally warm and dry (Mir \& Mirshekari, 2015: p. 8).

An applied, descriptive, and analytical study was performed. The sample size consists of seven S \& B cities. The area under consideration is 181,785 square kilometer and population density is 13 per $\mathrm{km}^{2}$. Life expectancy, education, and income are three main human development indictors in the United Nations Human Development. In this article, Students, Educational Employees, Administrative Employees, Total number of Employees, Schools, and Class are utilized to study the educational indicator. Documentary method was utilized to collect data. Desk study was performed through libraries, the extraction of references, and statistics including S \& B educational statistics covering the course 2011 to 2012 in order to determine the development in mentioned cities. According to the importance of indicators, limited access, and the fact that the acceptability of indicators is difficult and sometimes impossible by experts, we tried to utilize international criteria. Therefore, Morris model is utilized to measure educational development of cities due to the fact that its mathematical nature, the capability of integrating indicators, and development variables are extensively used in the development determination of cities. Development Index (Figure 3 \& Figure 4) is analyzed in five levels: very high, high, medium, low, and very low. 


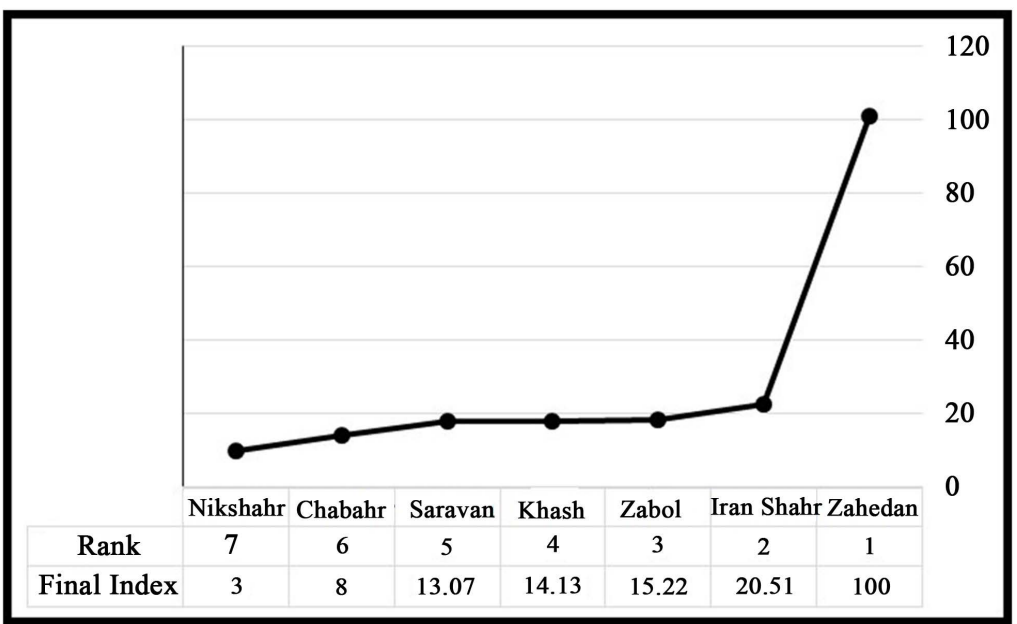

Figure 3. Final educational development Index and rank in Sistan and Baluchistan. Source 2: Author.

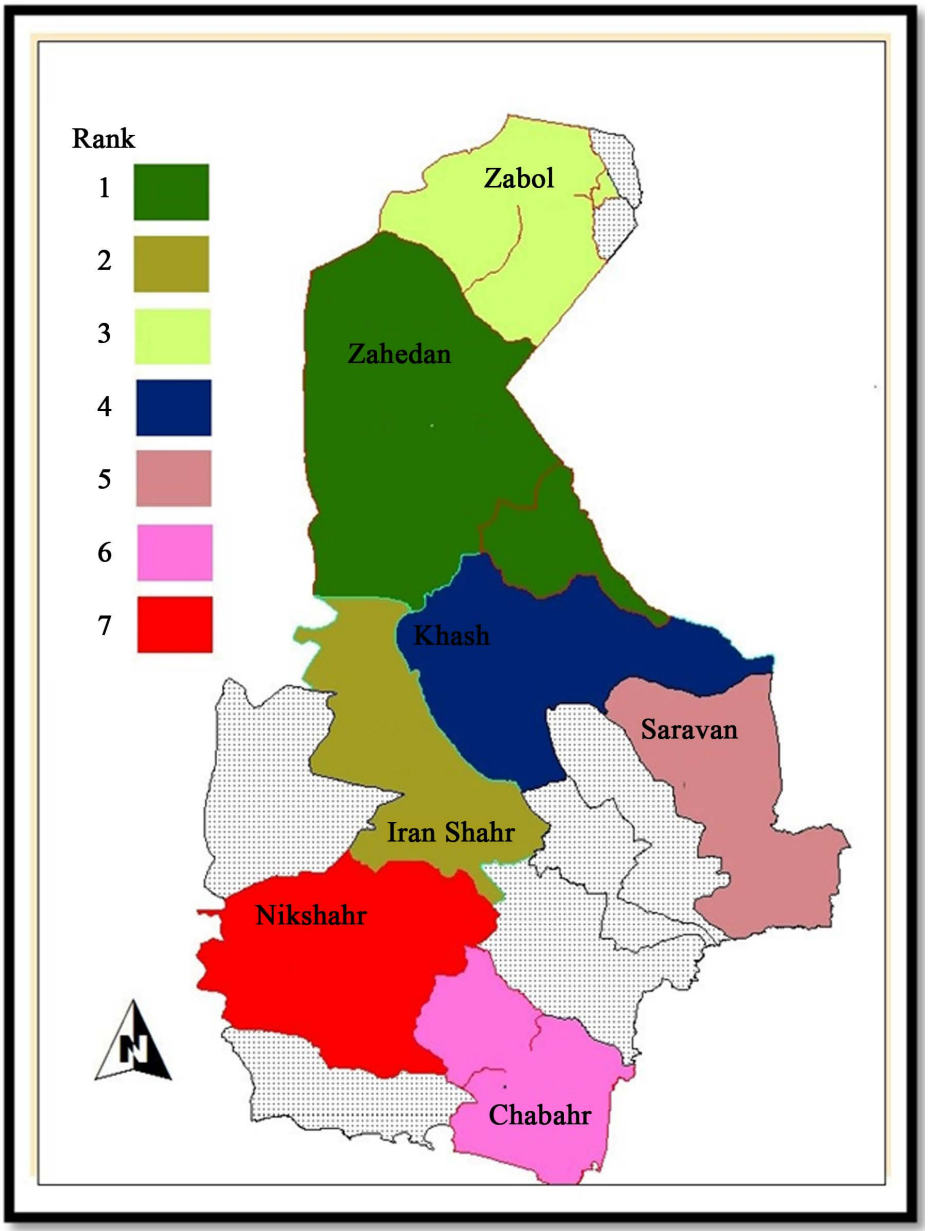

Figure 4. Final rating of development and tank in Sistan and Baluchistan. Source 3: Author.

S \& B Statistics were utilized to determine the level of educational development. Morris model was used to analyze data, determine the level of development, and rank the cities. GIS was also applied to show the level of development. 


\section{Total of Three Educational Courses}

Table 1 lists educational development index for all three educational courses calculated by Morris Model. The results are as follows.

\section{Final Educational Development Index in All Three Courses}

Table 2 lists Final educational development Zahedan is of the highest (100) and Nikshahr is the lowest (3). After Zahedan, there are Chabahar (20.51), Saravan (15.22), Khash (14.13), Zabol (13.07), and Iranshahr (8).

\section{Educational Development Levels in Sistan and Baluchestan}

According to Table 3, educational development levels consist of five levels: very high, high, medium, low, very low. The corresponding ranges are 80 - 100, 60 - 80, 40 - 60, 20 - 40, and 0 - 20, respectively. As it can be seen, Zahedan is in "very high development” level, while Iranshahr is in level 4. Zabol, Khash, Saravan, Chabahar, and Nikshahr are in "very low" level of development.

Table 1. Statistics in three levels.

\begin{tabular}{|c|c|c|c|c|c|c|}
\hline $\begin{array}{c}\text { Variables } \\
\text { City }\end{array}$ & $\begin{array}{c}\text { No. } \\
\text { of students }\end{array}$ & $\begin{array}{c}\text { Educational } \\
\text { employees }\end{array}$ & $\begin{array}{c}\text { Administrative } \\
\text { staff }\end{array}$ & $\begin{array}{c}\text { Total } \\
\text { employees }\end{array}$ & $\begin{array}{c}\text { No. of } \\
\text { schools }\end{array}$ & $\begin{array}{l}\text { No. } \\
\text { of classes }\end{array}$ \\
\hline Iran Shahr & 38140 & 1666 & 372 & 2038 & 260 & 1430 \\
\hline Chabahr & 26033 & 1163 & 157 & 1320 & 168 & 1121 \\
\hline Khash & 25718 & 1077 & 292 & 1369 & 272 & 1038 \\
\hline Zabol & 31252 & 1439 & 346 & 1785 & 175 & 1289 \\
\hline Zahedan & 116746 & 4992 & 1256 & 6248 & 539 & 4426 \\
\hline Saravan & 28364 & 1155 & 214 & 1369 & 250 & 1128 \\
\hline Nikshahr & 14087 & 557 & 237 & 794 & 208 & 623 \\
\hline
\end{tabular}

Source 1: Statistics, Sistan and Baluchestan Organization of Education, 2011-2012.

Table 2. Final educational development index (D.I.) in all three courses.

\begin{tabular}{ccc}
\hline City & Development Index & Rank \\
\hline Zahedan & 100 & 1 \\
Iranshahr & 20.51 & 2 \\
Zabol & 15.22 & 3 \\
Khash & 14.13 & 4 \\
Saravan & 13.07 & 5 \\
Chabahar & 8.00 & 6 \\
Nikshahr & 3.00 & 7 \\
\hline
\end{tabular}

Source 1: Author.

Table 3. Educational development levels in Sistan and Baluchistan province according to Morris Model.

\begin{tabular}{ccc}
\hline Educational development Levels & Development Index & City \\
\hline Very high & $80-100$ & Zahedan \\
High & $60-80$ & - \\
Medium & $40-60$ & Iranshahr \\
Low & $20-40$ & Khash, Zabol, Chabahar, Saravan, Nikshahr \\
Very low & $0-20$ &
\end{tabular}

Source 4: Author. 


\section{The Results of Morris Model to Determine Rank and Development Level}

Education has traditionally played an important role in the development of countries. Therefore, governments need to pay a special attention to education. Education enables low-income class to improve their positions in the market. In turn, it would be effective in the development level of countries. The aim of ranking is to help appropriate educational development policies and to eliminate deprivation. As many as 18 indicators were utilized to rank Sistan and Baluchistan cities educationally using Morris model in 2011. Some fundamental inequalities are observable among these indicators. According to Morris Model, it is concluded that Zahedan is in the first level of development (very high). Iranshahr is in level 4 (low) and Saravan, Khash, Zabol, Chabahar, and Nikshahr are in level 5 (very low). According to the results, Zahedan scored the top as the growth center of the province and Nikshahr was the lowest concerning educational development. The causes of regional inequalities lie in natural, economic, political, tribal, and cultural factors as well as failure of planning which have affected economic, social, cultural, political, and even educational performances, leading to backwardness in Iran. Therefore, central parts of Iran enjoy political attention due to appropriate geographical locations, playing an important role in the development. As the number of frequencies rises, development, in turn, increases. For the classification of cities in terms of priorities for further actions, they were utilized in five levels of development. As a result, Zahedan is in the first level of development (very high). Due to its political and administrative centrality, Zahedan has been able to consolidate its rule, enjoying by far higher educational development indicators. Due to far distance from Zahedan, which is the center of planning, other mentioned cities which are in very low and low development need to be the priorities for educational development, respectively as a result of natural features and cultural and ethnic issues. As we can see, Zahedan has grown by attracting facilities and resources, leaving fewer impacts on other cities. Allocation of financial resources and employment of human resources are required to meet these inequalities. This way, it would lead to educational promotion in order to provide the platform for growth.

\section{References}

General Directorate of Education-Sistan and Baluchistan (2012). Education Statistics in Sistan and Baluchestan.

Mir, A. R., \& Mirshekari, L. (2015). Sistan and Baluchestan Province. Tehran: Iran Text Books Press.

Saraki, N. (1996). Determining the Level of Development in Cities in Kermanshah, Iran. Journal of Economy Findings, 57, 53-57.

Tavakoli, M., Reza, A. et al. (2012). Educational Justice Development or Educational Complexes. Collection of First Conference on Urban Educational Complexes. 